\title{
LA EFEMÉRIDE DEL 25 DE SETIEMBRE
}

Lic. Wilder Sequeira Ruiz - Asesor Nacional de Estudios Sociales

Lic. Jorge Cartín Obando. Asesor Regional de San José de Estudios Sociales

\section{LA LLEGADA DE LOS EUROPEOS A COSTA RICA: GRANDES CAMBIOS SOCIOCULTURALES.}

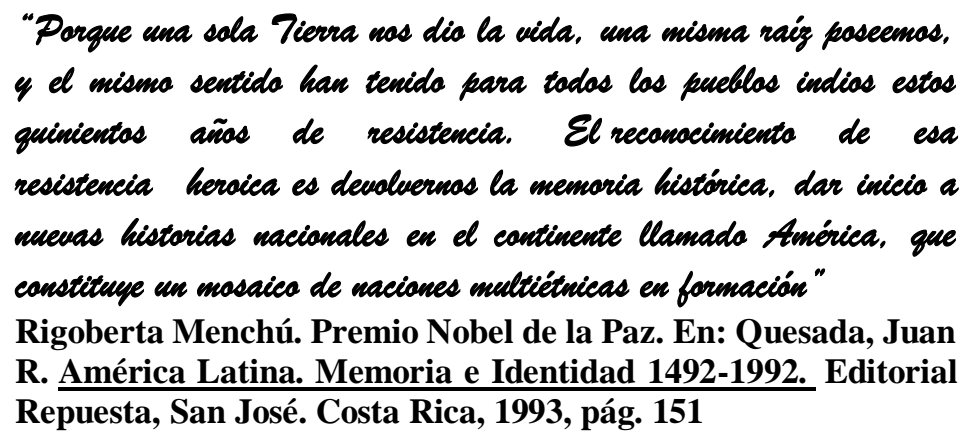

\section{INTRODUCCIÓN}

Al iniciar el presente artículo es importante retomar y explicar el carácter, naturaleza y función de la Ley N. 7426 del 21 de Setiembre de 1994, que conmemoraba el Día del Descubrimiento y de la Raza iA qué obedeció esta modificación?

Al igual que en América Latina, en Costa Rica a partir de la segunda mitad del siglo XIX, se desarrolló un proceso de consolidación de los Estados nacionales, bajo el sustento del proyecto político- económico del liberalismo. La élite política liberal para legitimar sus ideas acerca del marco político organizativo de la sociedad, volvieron su mirada al período de contacto y resistencia indígena ante los europeos. El propósito básico era rescatar a las poblaciones autóctonas ensalzando un pasado de lucha heroica que ayudara a que "el común" interiorizara un sentimiento nacionalista. Esta idea de exaltación tuvo su manifestación material en obras monumentarias, efigies en monedas, arte filatélico, pinturas, literatura, poesía, emblemas patrios, canciones populares, entre otras.

Sin embargo, los grupos oligárquicos liberales no eran consecuentes con su discurso. Así, en su vida cotidiana tenían arraigados los patrones culturales europeizantes. De esta manera, a lo largo de las celebraciones de los centenarios que conmemoraban el "Descubrimiento de América", se fue articulando una visión denominada "leyenda blanca" que en esencia, consistió en resaltar sólo los aportes más significativos que trajo consigo el proceso de conquista y colonización que llevaron a cabo los españoles. Esta visión quedó oficializada en la IV Exposición Histórica- Americana celebrado en Madrid el 12 de Octubre de 1892, en la cual participó la mayoría de los países hispanoamericanos-.

Estas pomposas celebraciones impactaron en gran medida en la sociedad de la época, ya que se magnificaba lo foráneo y marginaba lo autóctono. Los medios 
difusores de ideas de la época, principalmente revistas, boletines, libros y periódicos, jugaron un rol determinante en la divulgación de esta concepción. Lo anterior se consolidó con la participación del sistema educativo formal, cuya organización estaba sustentaba en contenidos y conmemoraciones que solo toman en cuenta como sujetos protagónicos a quienes realizaron la conquista y la colonización de América Latina, planteándose un enfoque parcializado de este hecho histórico e invisibilizando a otros grupos étnicos: indígenas, negros, mulatos y mestizos.

\section{¿POR QUÉ SE DESARROLLÓ LA EXPANSIÓN COMERCIAL EUROPEA DURANTE LOS SIGLOS XV Y XVI?}

Con la decadencia económica y política del imperio romano, cuyo escenario era el Mar Mediterráneo, surgió un nuevo polo de desarrollo en las costas de la Europa Noratlántica, lideradas inicialmente por Portugal y España. Para comprender este proceso histórico es necesario plantear que se conjugaron una serie de factores políticos, comerciales, técnicos y científicos que posibilitaron la conformación de dos importantes imperios marítimos, que ampararon su poderío, tanto en la existencia de academias (Escuelas de Sagres en Portugal ) y flotas navales, así como de la unificación rápida de un Estado- Nación, gracias a la legitimación que la Iglesia Católica otorgaba a las monarquías absolutas fundamentadas en el "derecho divino".

En el caso español, esta unificación política se facilitó, debido al matrimonio de los reyes representantes de dos reinos grandes o poderosos como sucedió con Fernando de Aragón e Isabel de Castilla. A partir de esta unificación se generó la reconquista de aquellos territorios todavía en manos de los musulmanes. Grandes sectores de la población ibérica, se vieron obligados a convertirse al catolicismo, o de lo contrario debían de refugiarse en las costas africanas al sur del país.

Es importante tener presente que la expansión ultramarina de los portugueses y españoles fue el resultado de la conjugación de una serie de eventos, en donde lo político se convirtió en uno de esos factores (fusión del Estado Español como consecuencia el matrimonio de los llamados Reyes Católicos).

Otro de los factores relevantes fueron los intereses comerciales por dominar las rutas marítimas de acceso a las materias primas, que se consideraban más importantes para el intercambio de bienes. Las de uso común como la sal, pólvora, pimienta, cominos, nuez moscada, canela, clavos de olor, entre otros. Los bienes suntuarios como perfumes, seda, joyas, oro, incienso, maderas finas, alfombras, cerámica fina y esclavos.

\section{¿Cuáles fueron otros de los factores desencadenantes de la expansión comercial europea?}

Desde mediados del siglo XV habían comenzado a formarse las primeras escuelas de navegación. Una de las más famosas, la fundó Enrique el Navegante, Rey de Portugal. Estas escuelas se especializaron no solo en la preparación de marinos y de los puestos principales de la cadena de mando, sino que también se dedicaban a la investigación náutica, encabezadas por especialistas en la materia.

Por lo tanto, estas academias financiadas por los monarcas, se dedicaron a perfeccionar el instrumental cartográfico existente. 
Por ejemplo, se pueden citar el astrolabio, que busca la medición de la posición de las estrellas con respecto al horizonte, y la brújula que consiste en una aguja imantada que marca permanentemente el punto cardinal norte.

FIG. No.1 Cristóbal Colón manejando un astrolabio. Fuente: Cristóbal Colón. Diario de abordo.

Asimismo, se pueden citar las cartas náuticas y terrestres de Marco Polo, el planisferio perfeccionado por Gerhard Mercator, la idea de la redondez de la tierra planteada primero por Erastótenes en la Antigüedad, retomada por Claudio Ptolomeo y perfeccionada por los árabes en el siglo XV. Finalmente se puede mencionar una mejoría importante en la construcción de naves denominadas carabelas, las cuales tenían como ventajas la rapidez, su capacidad de carga de hombres y alimentos, aspectos que le permitían una importante autonomía, con respecto a la distancia de los puntos de partida. Al mismo tiempo, las carabelas portaban cañones para su defensa, pólvora, arcabuces,. etc.

FIG. No.2 Las carabelas muestran una mejoría importante en la construcción de las naves. Fuente: Cristóbal Colón. Diario de abordo.

\section{LOS EUROPEOS EN AMÉRICA}

La llegada de los europeos a América y el conjunto de hechos que acontecieron posteriormente en el contexto costarricense, han tenido una interpretación que ha sobrevalorado los aportes de una de las partes involucradas en este proceso. Vale decir que un documento como la Cartilla Histórica del historiador Ricardo Fernández Guardia, prácticamente mitificó la llegada del europeo a América, invisibilizando a los pueblos autóctonos existentes al momento del contacto Por ello, recientemente los científicos sociales desde distintas ópticas y especialidades, han reinterpretado los acontecimientos y los han puesto en su justa dimensión.

En efecto, el arribo de los españoles a América, originó una serie de cambios económicos y socioculturales, que dieron como resultado una sociedad mestiza y pluricultural. Por esta razón, se le ha llamado a América., el continente "cobrizo" o el "crisol de culturas". Desde este punto de vista es inaceptable la afirmación de que los aportes culturales provienen de un sol9o grupo étnico, todo lo contrario, los 
legados se mezclan originando una riqueza y diversidad cultural, poco usual en el planeta.

\section{LA HERENCIA CULTURAL DE LOS PUEBLOS INVOLUCRADOS EN EL PROCESO DE LA CONQUISTA Y COLONIZACIÓN DE AMÉRICA.}

Los pueblos amerindios aportaron a la humanidad diversos avances. Practicaban una agricultura diversificada y con sistemas de irrigación. Los diversos cultivos americanos de tipo agrícola son de uso común en el mundo actual, tales como el maíz y sus derivados, el cacao, el tabaco, el tomate, chile, f4rijoles, el ayote y un sinnúmero de árboles frutales: papaya, aguacate, piña, zapote, guayaba, sandía, nance, jocote: plantas tintóreas como el palo de brasil y la mora, añil o jiquilite, achiote, y en tubérculos: la papa, yuca, tiquisque y el ñame.

Los pueblos amerindios también se destacaron por haber alcanzado un nivel de desarrollo civilizatorio significativo, evidenciado en los conocimientos astronómicos; tales como el calendario maya de 365 días, el uso del cero, la construcción de edificios monumentales o ciclópeos: palacios, templos y pirámides, diseñados con una precisión matemática y astronómica asombrosa, que aún hoy en día resultan enigmáticos para los investigadores.

Hacia agosto de 1492, la empresa colombina con la inversión de centenares de miles de maravadíes se hizo realidad cobrando un papel determinante la monarquía absoluta española, que aportó la mayoría de la inversión.

El soporte jurídico de esta empresa comercial, lo dieron las llamadas Capitulaciones de Santa $\mathrm{Fe}$, en las cuales se establecía que la monarquía ot monarquía otorgaría al Almirante Cristóbal Colón, el 10\% de las riquezas generadas en los territorios conquistados. Además, se le investiría con el rango de "Caballero" y de esta forma recibiría el trato social de "Don", al igual que a sus descendientes.

Fig. No.3 Escudo de armas concedido por los Reyes

Católicos a Cristóbal Colón. Fuente: Cristóbal

Colón. Diario de abordo

Luego de más de dos meses de zozobra en alta mar, inesperadamente , inesperadamente Rodrigo de Triana gritó: ¡Tierra a la vista; los españoles desembarcaron en la isla Guanahaní un 12 de Octubre de 1492, que Colón llamó San Salvador, y que hoy en día forma parte de las Islas Bahamas, en el Mar Caribe.

Fig. No.4 Ruta el primer y cuarto viaje del Almirante Cristóbal Colón. 
Así se inició una época de grandes transformaciones socioculturales, con lo cual la cultura del Viejo Mundo (Europa), entró en contacto con las culturas aborígenes milenarias del Nuevo Mundo (América). Lo anterior daría como producto una integración de diversidad cultural porco usual en el planeta, de dimensiones insospechadas para los pobladores americanos.

¿ Por qué se habla de una diversidad cultural que influyó tanto en la modificación del habitat natural, como el humanos en América y en Europa?

A los aportes que legaron las culturas americanas deben mencionarse los introducidos por los europeos: el consumo de carne vacuna, de cerdo, de pollo, la harina de trigo, el vino, los cítricos, el arroz, la pólvora, la religiosidad católica, la noción de la propiedad privada de la tierra, entre otros.

En un principio la organización imperial hispana originó la formación de las llamadas "Dos Españas". Una con plenos derechos, que consumía carne y vino, que practicaba la agricultura comercial, que defendía la propiedad de la tierra con personas, que gozaban de una libre circulación por los territorios, andar armados y a caballo. Mientras que la otra España, la indígena, poseía una propiedad ejidal (comunal) de la tierra, la cual se caracterizaba por el consumo del maíz y tenía sus derechos disminuidos.

Para mediados del siglo XVIII, se dio una recuperación de la población indígena y al mismo tiempo se profundizó un proceso de mestizaje que permitió el crecimiento mayoritario en términos comparativos. Esta mezcla de grupos étnicos originó al mestizo, que era la mezcla entre español e indio; el mulato que resultó de la combinación entre negro y blanco y el zambo mosquito fue el producto del cruce entre indio y negro.

En Costa Rica, al igual que en el resto de América Latina, conforme avanzó el siglo XIX, el mestizaje tomó aún más fuerza y algunas poblaciones como en el caso del Valle Central, sufrieron un proceso de "blanqueamiento", lo cual no indica que los rasgos mestizos originales se hayan perdido totalmente.

En el caso de otras regiones como Guanacaste, el mestizaje de españoles, indios y negros, originó el llamado "cholo guanacasteco". En cuanto a la región Atlántica que albergo mayoritariamente a la población negra, su situación de tradicional aislamiento, le permitió a sus pobladores conservar sus rasgos físicos y culturales. Por otra parte, el componente poblacional indígena, se refugió principalmente en la región e Talamanca. Otros grupos se refugiaron en la región Norte los Malekus y en el Pacífico Sur, los Borucas, Térrabas y Guaimíes.

Esta diversidad cultural fue invisibilizada por largo tiempo, ya que los estudios históricos y los textos de carácter escolar y universitario difundían concepciones que sobrevaloraban los aportes culturales de los españoles. No sorprende entonces, que la sociedad costarricense, al igual que el resto de América Latina, estuviera fascinada por los modelos culturales europeizantes y se renegara de lo autóctono. 
Esta línea de pensamiento, hasta hace poco dominante en el medio escolar y universitario, fue cuestionada por estudios de alto rigor científico, que han puesto sobre el tapete la realidad de los datos históricos.

Fue tal la necesidad de desarrollar el cambio metodológico y didáctico de la forma de abordar la historia que se hizo indispensable la promulgación de la Ley 7426 de Setiembre de 1994 que estableció el "Día de las Culturas"-

Esta ley deja entrever la variedad e protagonistas, los cambios socioculturales que hoy día forman parte de la idiosincrasia del pueblo costarricense.

\section{LOS ESPAÑOLES EN QUIRIBRÍ}

La evidencia histórica, antropológica yt arqueológica, permite establecer con precisión que los españoles arribaron a la costa caribeña de Costa Rica en el cuarto viaje de Cristóbal Colón, el 25 de Setiembre de 1502, específicamente en la isla de nombre Quiribrí, en vez del nombre comúnmente aceptado de Isla Uvita. Al mismo tiempo, a la costa caribeña limonense, que los españoles denominaron, "Cariari”.

\section{CLASIFICACIÓN DE LAS ÁREAS CULTURALES AMERINDIAS}

Los arqueólogos en el caso de América, han clasificado a las sociedades autóctonas en regiones culturales tales como: Mesoamérica, Intermedia y Andina. Cada una de estas áreas comparte una serie de rasgos que les define y diferencia de otras, desde el punto de vista económico, político y sociocultural.

En el caso costarricense por constituir un "puente biológico y cultural", entre el Norte y el Sur, se facilitó un intercambio dinámico de aspectos culturales de los asentamientos humanos que ocuparon el territorio nacional. No obstante, los rasgos en Costa Rica del tipo mesoamericano, se encuentran ubicados en la Región de la Gran Nicoya, la cual comprende desde el Istmo de Rivas, hasta las Islas del Golfo de Nicoya y el actual territorio de Guanacaste y parte de Puntarenas en el sector oriental del mismo golfo.

Los rasgos mesoamericanos más importantes que posee Nicoya son: el desarrollo de la agricultura diversificada: maíz, frijoles, cacao, tabaco, algodón, añil, achiote, ayote, chile, tubérculos como la papa, la yuca, el ñami y el tiquisque,; frutales como la papaya, aguacate, zapotes, jocotes, nances, guayaba, tamarindo, entre otros.

ESPAÑOL REVISANDO A CALIDAD DE LA PRODUCCIÓN CACAOTERA

Fig. No 5. Producción cacaotera. Fuente: Historia del Istmo Centroamericano: CECC. 
También Nicoya desarrolló una división social del trabajo, o sea, que cada persona tenía una función específica en la sociedad. Por ejemplo, gobernantes (caciques), guerreros o militares, sacerdotes, comerciantes, agricultores, artesanos y esclavos.

La Gran Nicoya, vio florecer la estructura de la ciudad con su mercado, plaza, centros ceremoniales, templos y cementerios.

En la plaza principal estaban las viviendas de los gobernantes, sacerdotes y guerreros.

Se cree que Nicoya fue fundada a orillas de la desembocadura del río Zapandí, hoy Tempisque, en el año 800 a.d.C.; posteriormente en 1524, Nicoya jugó un papel fundamental en la conquista de Nicaragua y Costa Rica, ya que las expediciones se apertrechaban de alimentos y de tamemes ( hombres usados como mulas de carga y guías ).

En la gran Nicoya, en el ámbito artístico, sobresalen los objetos de cerámica con motivos relacionados con la fauna y el paisaje natural. Las figuras poseían caracteres zoomorfos y antropomorfos y los colores evolucionaron desde una cerámica monocroma a una policroma. También se distinguieron en las técnicas de trabajo del jade muy sofisticadas, utilizando colores como el verde, rojo y azul. El material utilizado en los trabajos de jade, es la llamada obsidiana.

Finalmente, se puede precisar que realizaron trabajos con piedra, dentro de los que sobresalen los meates.

Las creencias religiosas predominantes estuvieron ligadas con la región mesoamericana. Por ejemplo, el Dios Quetzalcoatl (Serpiente Emplumada).

El resto del territorio de Costa Rica fue incluenciado por las culturas andinas y en menor grado por las del caribe.

En el sector de Diquis y en el Central, se han encontrado ciudades del período Antiguo de Costa Rica. La más estudiada es Guayabo en Turrialba que constituyó un centro urbano importante, el cual se encuentra en proceso de investigación. Dicha ciudad presenta un conjunto de construcciones, tales como: calzadas, puentes, centros ceremoniales, promotontorios para el ejercicio de rituales, acueductos ( que aún funcionan)

Fig. No 6. En la Región de Diquis se han encontrado diversos petrolifos. Fuente Costa Rica en Mapas. Tambor. Publicaciones Los Olivos.

En la región Pacífico Sur se encuentran algunas ciudades, donde sobresalen promontorios de piedra que se suponme son cementerios o sitios funerarios que por falta de patrocinio, aún no han sido excavados y estudiados a fondo. Sobresalen además las conocidas esferas gigantes de piedra, que a la fecha de hoy, constituyen un misterio por resolver. 
Fig. No 7 Esfera gigante de piedra de la Región de Diquis. Fuente Pueblos indígenas de Costa Rica. Ediciones Tikal. S:A:.

Los sitios arqueológicos se encuentra principalmente en el valle de Diquis, a orillas del Río Grande de Térraba y las islas del delta del mismo río; así como las islas costeras; tales como Violín y la isla del caño.

Fig. No 8. Reservas Indígenas Actuales. Fuente Los Pueblos indígenas de Costa Rica. Ediciones Tikal. S:A:.

En la Región Central y a de Diquís, se desarrollaron áreas culturales que evidencian un desarrollo sociocultural complejo. Aquí se desarrolló una agricultura basada en los tubérculos, el pejivaye y en menor medida el maíz.

Desde el punto de vista artístico se destacó el trabajo en piedra, como los metates típo trípode y el oro trabajado bajo el proceso de la "cera perdida".

Al igual que en la región cultural mesoamericana, estas sociedades desarrollaron una religión politeísta sustentada en un profundo respeto por la naturaleza.

\section{RASGOS SOCIO-CULTURALES QUE EVIDENCIAN UN DESARROLLO CIVILIZADO DE LAS SOCIEDADES ABORÍGENES COSTARRICENSES}

Existen una serie de rasgos culturales prototípicos que permiten y hablar de la transición de las sociedades primitivas a la civilización. En efecto, un pueblo alcanza un nivel civilizatorio cuando presenta una estructura de poder significativa (gobierno cacical), una organización de las tareas laborales (división social del trabajo), un desarrollo de técnicas complejas para la elaboración de objetos de cerámica, la agricultura, la escritura acompañada de un sistema socialmente aceptado de fonemas, la vida en las ciudades con su respectivo régimen organizado para construir obras públicas: puentes, caminos, templos, acueductos, promontorios de piedra, centros ceremoniales; desarrollo del intercambio comercial bastante dinámico, clase sacerdotal y militares o guerreros y un desarrollo artesanal importante.

\section{CONCLUSIÓN}


En virtud de lo anterior, se puede afirmar que las sociedades aborígenes costarricenses en el momento del contacto con los europeos (siglo XVI), ya habían alcanzado un alto grado de desarrollo civilizatorio intermedio.

En la actualidad los pueblos indígenas viven en reservas: Matambú, Boruca, Conte, Curica, Guaymí, Guatuso, Quitirrisí, Talamanca, Bribrí, Curré, Osa, Telire, Cabagra, Coto Brus, Ujarráz entre otras. La mayoría practicaban una agricultura de subsistencia que la complementan con la caza y la pesca. Otros realizan diversas actividades artesanales. Sus diferentes productos son adquiridos a muy bajo precio. Carecen e caminos, lo que agrava su situación de aislamiento.

Los indígenas actuales, no disfrutan de servicios públicos del Estado costgarricense como sí lo hace la mayor parte de la población. Además, están siendo amenazados en su propia tierra, debido a los procesos de deforestación y a las exploraciones petroleras.

Uno de los aportes esenciales de las sociedades aborígenes costarricenses, es el desarrollo de sus actividades económicas y culturales en armonía con la naturaleza.

Ellas aprovecharon el recurso que les brindaba el medio sin destruir la tierra, porque eran conscientes que ésta era su hogar. Esta es la lección que en la actualidad debemos de aprender y practicar. 


\section{SUGERENCIAS DIDÁCTICAS}

A continuación se brindan una serie de sugerencias para el abordaje didáctico de esta temática, según los diferentes ciclos educativos; desde la educación primaria hasta la secundaria. Lo anterior no significa, que el docente en calidad de mediador del proceso de enseñanza aprendizaje, no pueda hacer las adaptaciones pertinentes, según su planeamiento escolar.

Es importante señalar desde la perspectiva didáctica que en la conmemoración de fechas patrias, se planteen las sugerencias que constituyan verdaderos espacios de memoria colectiva y reflexión. Es vital que los actos cívicos tengan una participación masiva de los educandos en donde el hecho histórico en estudio, sea visualizado desde carios puntos de vista.

La mediación pedagógica debe brindar posibilidades para que los educandos discutan y se formen una opinión para que se apropien significativamente los conocimientos.

Se deben fomentar momentos de aprendizaje dinámicos, en los cuales, se logre debatir ideas y posiciones o puntos de vista distintos. Por ejemplo, organizando foros, debates, sociodramas, juicios históricos, biografías críticas, estudio de casos, presentación de títeres. Si esto se lleva al aula, la participación del alumnado debe ser más integral, coherente y responsable. En este sentido, la mediación y la motivación de los docentes, es esencial.

\section{PRIMER CICLO}

En el Primer Ciclo, se recomienda no perder de vista la dimensión lúdica del aprendizaje. Es importante que los niños (as) utilicen los juegos para aprender.

En este sentido, deben explotarse sus potencialidades artísticas y cognitivas, mediante la combinación de la expresión oral, el canto, las dramatizaciones, el baile, entre otras; y una mayor recreación así como disposición para aprender haciendo.

\section{CONSTRUYENDO NOCIONES.}

Para acercar a los niños (as) al hecho histórico, es importante que el docente busque o elabore dibujos, láminas ilustrativas, objetos de material seguro y resistente (madera, plástico, cartón) alusivos a la efeméride.

Seguidamente los materiales didácticos, deben ubicarse en un lugar visible del grupo o aula, de manera que, los niños (s) puedan identificarlos y palparlos, con el propósito de que se familiaricen con los recursos diseñados para este fin.

Una vez que se ha realizado este momento de aprendizaje, el docente puede poner a los niños a discutir acerca de lo visto o a escribir información en la pizarra, con la ayuda de organizadores gráficos de información, tales como mapas conceptuales o esquemas semánticos. Es importante en niveles de $2^{0}$ y $3^{0}$, poner a los niños (as) a realizar redacciones pequeñas, acompañados de dibujos para recortar o pintar.

\section{ACTIVIDAD DIDÁCTICA}


Se recomienda para los niños (as) de tercer grado, con la supervisión del docente, elaborar la silueta del mapa de Cosa Rica. Luego se divide en las Regiones Culturales del país. Posteriormente, con dibujos o recortes de revistas o periódicos, ubicar las figuras y objetos culturales según la región de que se trate.

\section{SEGUNDO CICLO}

En este ciclo, no debe perderse de vista la evolución socio- afectiva y cognitiva del educando, razón por la cual debe existir un adecuado balance en el estilo de aprendizaje que combine el juego con los conceptos. Los educandos necesitan proseguir con el canto, el baile, la declamación, el uso de los dibujos y los recortes.

Las actividades didácticas necesitan ser propositivas en un continuo aprender haciendo.

Debido al desarrollo de las destrezas intelectuales y psicomotoras, evidenciadas por los educandos, se recomienda al mediador inducirlos a elaborar de manera creativa, los materiales y / o recursos referidos al hecho histórico, en el propio contexto de aula.

\section{CONSTRUYENDO CONCEPTOS.}

Las actividades en este ciclo deben potenciar las habilidades relacionadas con la discusión o debate de ideas, ya sea mediante la creación de sociodramas, lluvias de ideas, videoforos, comentarios de texto que utilicen como "materia prima", canciones populares, textos literarios, poesías que den paso a puestas en común; en las cuales el educando, esté en plena capacidad de emitir juicios. Esto permite que desarrolle autonomía, iniciativa y creatividad, facilitando la toma de decisiones y la resolución de conflictos y problemas.

\section{CONSTRUYENDO HABILIDDES DE PENSAMIENTO}

Complete el siguiente diagrama de Ben, proponiendo las diferencias y similitudes entre la cultura europea y los aborígenes.
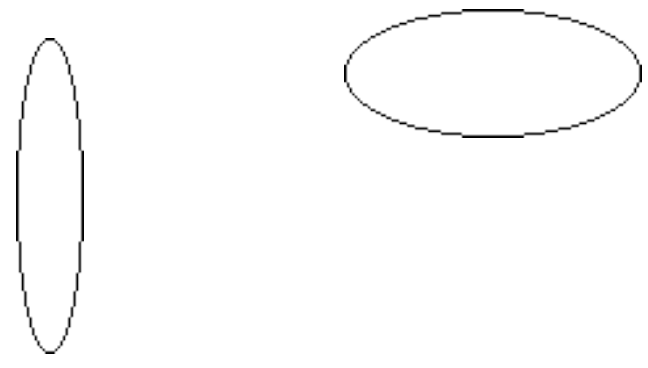

Complete las frases en el siguiente esquema semántico, basándose en la pregunta central (generadora). 


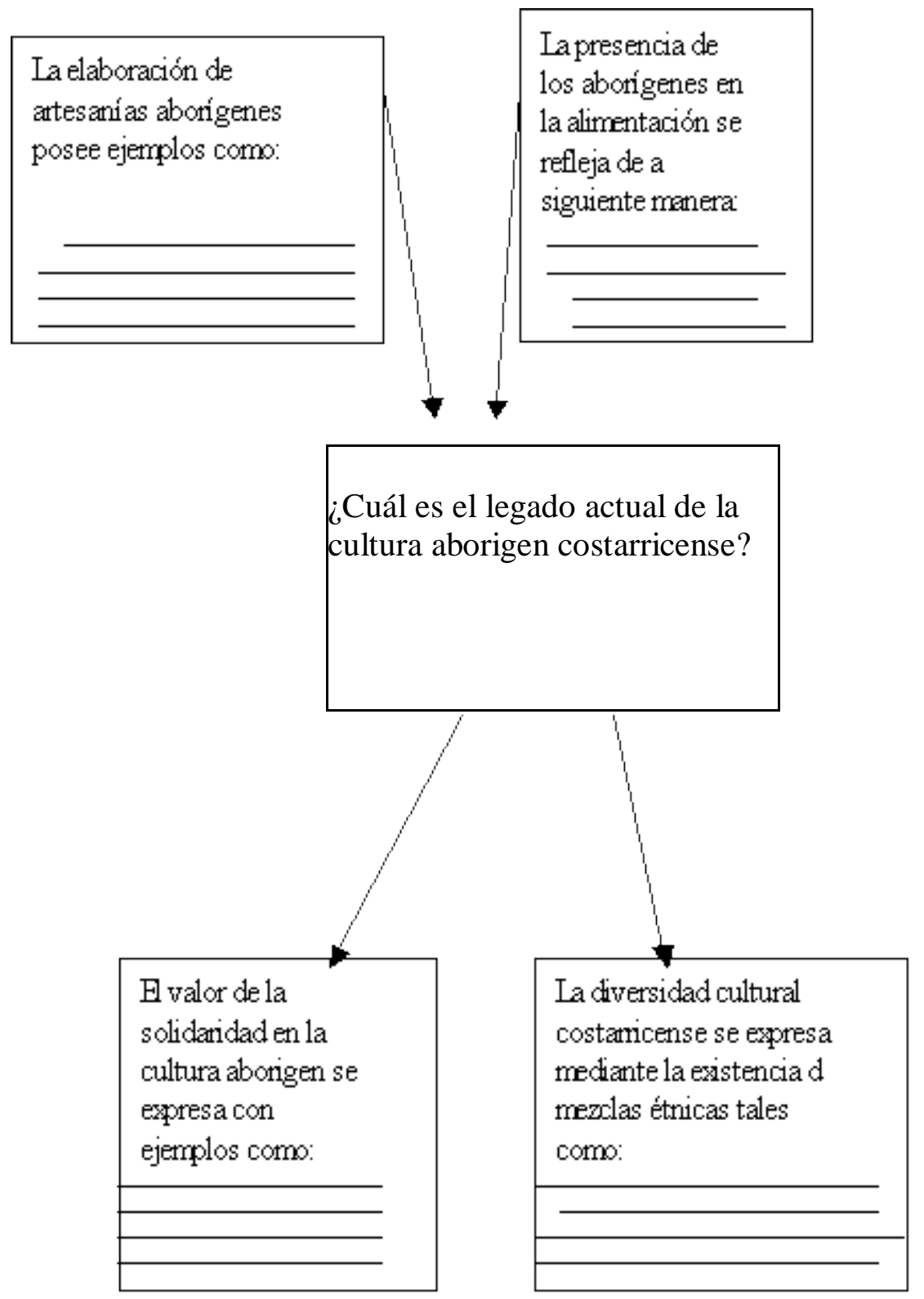




\section{CICLO}

Para Este Ciclo, el educando debe estar en capacidad de elaborar y reestructurar conceptos. También es importante que con autonomía e independencia pueda emitir juicios, sobre todo, en una asignatura como los Estudios Sociales que depende de un conocimiento razonado acerca de los hechos y procesos históricos. No está demás abonar, que se debe pensar en resolver continuamente disyuntivas, problemas, en donde es indispensable definirse a favor o en contra de alguna situación. Es por lo anterior que se habla de toma decisiones, habiendo hecho un análisis minucioso de los datos e informaciones que rodean el contexto de los fenómenos sociales, tanto temporales como espaciales.

\section{HACIA UN APRENDIZAJE PROPOSITIVO.}

\section{TARJETA DE CLASE}

Las tarjetas de clase se inscriben en el animito de los aprendizajes propositivos y constan de una afirmación principal alrededor de un dato o proceso históricogeográfico. Dicha afirmación se redacta de manera no ambigua, de tal forma que ayude al estudiante a tomar una decisión y justificar razonadamente su respuesta.

Esta técnica de trabajo facilita la organización y discusión de ideas y puede usarse de manera individual o grupal.

\section{EJERCICIO}

Afirmación:

"Las sociedades aborígenes costarricenses no llegaron a alcanzar un estadio de desarrollo civilizatorio, debido entre otras cosas a la ausencia de arquitectura monumental"

( ) De acuerdo ( ) Parcialmente de acuerdo ( ) En desacuerdo

Justificación:

\section{LA REJILLA CONCEPTUAL}

Este procedimiento heurístico consiste en presentar en rejillas separadas una serie o grupo de conceptos, de manera que el educando, pueda proponer la mayor cantidad de relaciones entre los mismos. 
EJERCICIO:

Relacione los siguientes conceptos:

\begin{tabular}{|l|l|}
\hline Expansión comercial europea & Nuevas rutas comerciales \\
\hline Culturas aborígenes americanas & Monarquía española \\
\hline
\end{tabular}

Con las ideas anteriores elabore un ensayo de normas del 15 renglones.

\section{EDUCACIÓN DIVERSIFICA}

En este Ciclo la mediación pedagógica del docente, debe buscar ejercicios de síntesis para los educandos. Es recomendable APRA $10^{\circ}$ y $11^{0}$ año, que se desarrollen comparaciones de procesos históricos o geográficos, con amplia utilización datos, los proyectos de investigación, las asignaciones y los trabajos extra clase y de aula, para que se conviertan en auténticos desafíos a la imaginación, ya que los educandos poseen herramientas conceptuales más consolidadas, razón por la cual, se profundiza la toma de decisiones bajo una óptica crítica.

\section{EL COMENTARIO DE TEXTO}

Consiste en determinar la idea central, las ideas secundarias y finalmente asumir una posición persona y / o grupal con respecto a lo leído.

\section{Ejemplo:}

"España es un país muy lejano, muy lindo, donde había una Reina que se llamaba Isabel la Católica; esta Reina entregó sus joyas para que Cristóbal Colón tuviera el dinero suficiente para poder venir con los españoles a descubrir América y a traernos su religión, su raza, su civilización, sus productos y nuestro hermoso idioma español, uno de los más bellos del mundo..."

Fernández de Montagné, Aida. "Doce de Octubre” En Boletín de Ande, 1967.

Basado en lo que usted ha leído, ¿Qué interpretación haría de esta cita textual? 
Idea Central

Ideas

Secundarias

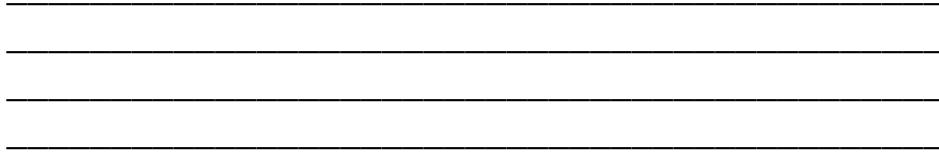

Comentario

Personal

\section{DESEMPEÑO DE ROLES}

Consiste en tomar el lugar de un personaje real o ficticio, fundamentado en una investigación previa. Tal procedimiento permite fortalecer actitudes y opiniones personales en función de un hecho histórico o geográfico. Esto le permite al educando, valorar en su justa media el contexto estudiado.

“En 1569, Preafán de Rivera, gobernador de la Provincia de Costa Rica, realizó la primera repartición de indios (encomienda), a pesar de que la monarquía española encabezada por el Rey Felipe II, desde 1542 había promulgado las Leyes Nuevas que prohibían la esclavitud del indígena en América. Dentro del grupo de indios repartidos al español Antonio Pereira y Cerna, se encontraba el indio Francisquillo Alcázar de 26 años, el cual fue separado de su familia, compuesta por su esposa y dos hijos. Francisquillo fue trasladado por la fuerza desde Talamanca a Nicoya, para ponerlo al servicio del encomendero" .

Caso ficticio: Sequeira y Cartín

Nota: Las movilizaciones poblacionales de indios de una región a otra fueron típicas en el período de Conquista y Colonización (siglo XVI y XVII) . Cf. Morel de Santa Cruz, . Pedro Agustín. Viajeros por guanacaste p.107

Escriba usted qué pensaría al respecto cada uno de los siguientes personajes.. Felipe II 
Francisquillo

Alcázar

La esposa de

Francisquillo

$$
\text { e }
$$$$
\text { Francisquillo }
$$

Un hijo de

Francisquillo

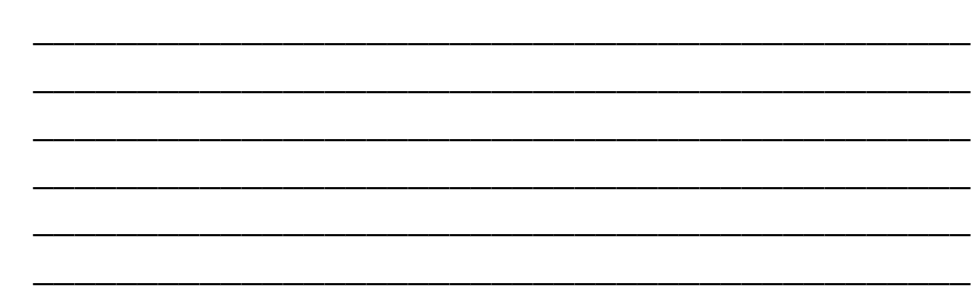

El Cacique de Nicoya

\section{GLOSARIO}

Astrolabio

Instrumento que establece la medición dela posición de las estrellas con respecto al horizonte.

Cartas Náuticas Cartas de navegación marítima

Cobrizo: Amerindio, moreno, bronceado, curtido.

Cholo guanacasteco: Cruce del español con el indio y el negro.

División social del trabajo: Cada persona tiene una función u oficio, específico que satisface ciertas necesidades de la sociedad.

El común: Gente del pueblo, común y corriente que no se destaca.

Gehard Mercator: 1512-1594 Matemático y geógrafo. Fundador de ka geografía matemática moderna y dio nombre a la "Proyección Mercator". 
Leyenda Blanca: Resalta solamente los aspectos positivos de los españoles en el proceso de Conquista y Colonización.

Leyenda Negra: Destaca las crueldades cometidas por los españoles contra los pobladores autóctonos de América.

Maravadíes: Moneda Española del siglo XVI.

Marco Polo: 1254-1324. Comerciante veneciano. Su libro es una especie de enciclopedia que detallaba ampliamente la geografía de Asia Oriental.

Mestizo: Mezcla entre el español y el indio.

Mulato: Cruce entre negro y español

Europa Noratlántica: Pueblos europeos que poseen costas en el Océano Atlántico. Ej. España, Portugal, Bélgica, Holanda, Francia, Alemania, Dinamarca, Noruega, Inglaterra.

Tamemes: Indios utilizados por los españoles como vestias de carga y para guía.

Zambo mosquito: Cruce entre negro e indio. 


\section{BIBLIOGRAFÍA}

Bozzoli V, María Eugenia. Et.Al. ¿12 de Octubre, Día de las Culturas?. Costa Rica: Una sociedad pluricultural. E.C.R., San José, Costa Rica, 1998.

Cabezas Alpízar, Gamaliel. (Compilador) "Día de la Raza", En Boletín de la ANDE. Departamento de publicaciones de ANDE. N.14-15-16, San José, Csota Rica. 30 de setiembre- 30 octubre, 1967.

Colegio T.P.A. de Talamanca., Proyecto de Investigaciones sobre la Historia Local del Cantón de Talamanca. 1981-1982 M.E.P., Departamento de Publicaciones San José, Costa Rica, 1983.

FUNCOOPA. Los pueblos indígenas de Cosa Rica. Historia y situación actual. Ediciones Tikal. S. A. San José, Costa Rica. 1999

Guevara B. Marcos. Et. Al ¿Quiénes somos? Costa Rica. Pluricultural y Multilingüe, EUNED. San José, Cosa Rica. 1992.

Morel de Santa Cruz, Pedro Agustín. "Visita apostóoica a la Provincia de Nicoya. 1751" En Viajeros por Guanacaste., Meléndez Chaverri, Carlos. Compilador. MCJ.D. San José. C. R. 1974 pp.99-107-

Muñoz Puelles, Vicente . (Comentado por) Cristóbal Colón. Diario de a bordo. Grupo Anaya. Editorial. Rey Andes Ltda.. Bogotá, 1995.

Ramírez R, Manuel. Nuestro tesoro natural. La Diversidad biológica de Costa Rica. Editado por INBIO, MÍRENME y MUSEO NACIONAL. San José, Costa Rica, 1993.

Sequeira Ruiz, Wilder y Cartín Obando, Jorge. Las sociedades indígenas de Costa Rica. MEP. San José, Costa Rica, 1998. 